\title{
Understanding the Relationship between Energy Consumption and Urban Form
}

\author{
By Bruno Osorio* \\ Nick McCullen ${ }^{\dagger}$ \\ Ian Walker ${ }^{\ddagger}$ \\ David Coley ${ }^{+}$
}

\begin{abstract}
A large proportion of energy demand comes from urban areas, mostly from buildings and transport, the use of which has impacts on climate and air quality through the emissions of greenhouse gases and other pollutants. The research in this paper investigates the relationship between the selected urban form characteristics and energy consumption in England, in order to understand how one influences the other. The influence of urban form is recognized in many aspects of cities, such as human behavior and transport dynamics. Consequently, it is also expected to have a significant impact on energy consumption and to be a key component in future urban sustainability. Urban energy consumption is calculated at a large geographic scale of analysis combining the consumption of both buildings and commute transport. Urban form indicators are obtained for the same land-parcels and correlations between the two calculated. The results demonstrate that a variety of urban form characteristics influence energy consumption. Some measures show little correlation with energy consumption, whereas other density measures show a significant scaling relationship. Therefore, density indicators such as population density are suggested as a means to explain urban energy consumption. Additionally, the results reveal that the relationship between energy consumption and urban characteristics follows a sublinear scaling relationship and hence show an economy of scale. This analysis suggests that better energy efficiency is achieved by areas with higher population density, which provides new insights to urban policy-makers and planners seeking to design strategies to cut carbon emissions and energy consumption.
\end{abstract}

Keywords: Correlation, Energy consumption, Scaling laws, Urban areas, Urban form.

\section{Introduction}

Urban areas are growing due to economic development and industrialization (Madlener and Sunak, 2011; Fonseca and Schlueter, 2015), with more people living in cities than ever before (Makido et al., 2012; Reinhart and Davila, 2016). As a result there is an ever increasing urban energy demand, which will only rise further as the growth of urbanization is expected

\footnotetext{
* PhD Student, University of Bath, UK.

${ }^{\dagger}$ Lecturer, University of Bath, UK.

${ }^{\ddagger}$ Senior Lecturer, University of Bath, UK.

${ }^{+}$Professor, University of Bath, UK.
} 
to continue (UN-DESA, 2014; Reinhart and Davila, 2016). Since the energy supply is largely derived from fossil fuels (Anderson et al., 2015) this rise in energy demand is tied to a greater contribution of urban areas to greenhouse gas (GHG) emissions (Dhakal, 2009; Lovelace, 2014) and results in negative consequences such as climate change and air pollution. Therefore, strategies are urgently needed to reduce the carbon-based energy dependency of cities. To implement mitigation strategies it will first be necessary to identify energy consumption patterns in cities and other urban areas. Buildings and transport are the two main contributors to the urban energy demand (Banister et al., 1997; Hickman and Banister, 2014), so measuring their consumption is of vital importance. The energy consumption of both buildings and transport is highly interdependent as a result of urban spatial layout influencing the building users' mobility and respective annual travel distances, which affects the carbon footprint of transport (Stephan et al., 2012). Transport networks in particular impact on the energy consumption of both buildings and transport (Hillier and Vaughan, 2007) by carrying individuals and goods between locations (Barthelemy et al., 2013). The parallel study of the energy consumption of both buildings and transport is thus necessary to prevent unintended outcomes of one-sided strategies by planners.

To implement mitigation strategies it will first be necessary to identify operational energy consumption patterns in cities and other urban areas. Buildings and transport are the two main contributors to urban energy demand (Banister et al., 1997; Hickman and Banister, 2014), so measuring their consumption is of vital importance. The operational energy consumption of both buildings and transport is highly interdependent as a result of urban spatial layout influencing the building users' mobility and respective annual travel distances, which affects, for example, the carbon footprint of transport (Stephan et al., 2012). Transport networks, in particular, have an impact on the operational energy consumption of both buildings and transport (Hillier and Vaughan, 2007) by carrying individuals and goods between locations (Barthelemy et al., 2013). The parallel study of the operational energy consumption of both buildings and transport is thus necessary to prevent unintended outcomes of one-sided strategies by planners.

To aid urban planners trying to both design new cities and redesign the existing ones to achieve better energy efficiency, it will be valuable to understand the relationship between operational energy consumption and urban characteristics. The research in this paper explores this relationship by looking for correlations and scaling laws between different measures of both operational energy use and selected urban form features. Moreover, the research is uniquely focused on a large scale of analysis, looking at the scaling over urban areas within cities, rather than between them. This is an original approach since the vast majority of previous research analyze the relationship between energy and urban form at smaller scales, i.e. studying individual cities or sets of cities (Mindali et al., 2004; Song and Knaap, 2004; Schwarz, 2010; Liu and Shen, 2011), or else boroughs/residential areas of large cities (Dieleman et al., 2002; Holden and Norland, 2005; Ewing and Rong, 2008). Although studies at a 
large scale have been published, these are mainly related to travel behaviour (Boarnet and Crane, 2001; Handy et al., 2005; Næss, 2012; Shim et al., 2006) given that, for example, neighborhood-scale enables a better understanding of the dynamics, impacts and needs of the sector. Overall, the research presented in this paper uncovers the variation that operational energy consumption can exhibit with selected urban form characteristics by means of power-law scaling analysis within the urban regions.

\section{Literature Review}

The research in this paper has two main aims: i) outline a new, simple energy metric; ii) analyze the relationship between operational energy consumption and selected urban form characteristics. As the energy metric is based on previous work (Osório et al., 2015; 2016) only a short overview is given here. This metric is useful as it combines the operational energy consumption of both buildings and commute transport energy, using a nondetailed energy estimate at a large scale and readily available official data, which may be used by policy-makers and planners as an initial estimate to outline actions to reduce or mitigate energy consumption. When studying the relationship between energy and urban form characteristics, the work is split in two parts: i) selecting urban form features, based on the concept of urban form and commonly used measures, as informed by pre-existing research; ii) understanding that relationship using a power-law scaling analysis between the two datasets, in order to identify the scaling regimes and how one dataset influences the other, and including the calculation of correlation coefficients to determine the strength of the relationship. The following section outlines a short review of energy consumption estimates, urban form concepts and the theory of scaling laws.

\section{Energy Consumption Estimation}

Estimating the energy consumption of buildings is a complicated process, which is only compounded when looking at that of a neighbourhood or network of buildings. At present there is no unique, best, approach to the problem. A common approach is setting up a model to represent the real world's complexity and obtain a better understanding of its dynamics. Numerous models have been introduced by the literature (Howard et al., 2012; Feng et al., 2013; Heiple and Sailor, 2008; Crawley et al., 2000; Gerber, 2014), but while enabling very detailed estimates of energy consumption, the complexity of the modelling procedure limits its large-scale application to large geographic areas. Additionally, the models demand a lot of input data that is not generally available for all cities or urban areas.

Calculating transport energy consumption is also not an easy task due to the sector's heterogeneity and a combination of diverse travel modes. Even though the transport sector is often considered a driving force of economic 
growth (Franc and Sutto, 2014; Tian et al., 2014), it is responsible for numerous problems such as congestion, pollution and other negative impacts, so many recent studies have been focused on reducing those impacts. As with buildings, the use of models is a common approach and are usually used to estimate and forecast future fuel consumption, transportation's $\mathrm{CO}_{2}$ and other GHG emissions, study travel behavior and many other transport-related activities (Travesset-Baro et al., 2016; Hao et al., 2015; Brand et al., 2012; Yin et al., 2015; Wang, 2008; Cappiello et al., 2002). These models vary in their framework, purpose and objectives: some deal with the whole transport sector, others focus on the freight or private car sub-sectors. In general, optimization and efficiency are key words used in transport energy use studies, aiming to introduce more efficient fuels or vehicles or other technological solutions that reduce transport's carbon output, mostly the passenger sub-sector (Gilbert and Perl, 2013; Chapman, 2007; Sperling and Lutsey, 2014; Brand et al., 2013; Qian and Eglese, 2016; Ajanovic et al., 2012).

Another major hindrance in estimating urban energy consumption is the definition of the urban boundaries. Different urban/rural classification systems exist and produce different figures for energy consumption. Urban boundaries change over time, but administrative definitions can be slow to follow (Tayyebi et al., 2011; Steinberger and Weisz, 2013; Marcotullio et al., 2014). These administrative boundaries of cities, in particular large cities, usually do not cover the whole urbanised area relating to a city. This also raises obstacles for planners and policy-makers who may have to use unreliable energy estimates to design actions to reduce/mitigate consumption (Steinberger and Weisz, 2013).

In this paper the definition of urban boundaries is avoided by using a large scale geographical unit developed for statistical purposes - Lower layer Super Output Area (LSOA) - that does not demarcate the limits of the cities. This enables the dynamics of cities and urbanised areas to be studied within such areas, without having to pre-define them. Furthermore, the combined energy use metric uses readily available official government data, and so it does not rely on using complex analysis of highly detailed datasets. This provides easy and accessible energy consumption estimates to planners and policy-makers using readily available data.

\section{Urban Form}

Using urban attributes to understand their relationship with energy consumption is built on the concept of urban form. Urban form has been used to uncover the consequences and challenges of urban development, as well as human impacts on the environment and cities (Alberti, 2005; Weng et al., 2007; Grimm et al., 2008). Energy consumption has also been shown to be influenced by urban form (Creutzig et al., 2015; Mindali et al., 2004; Poumanyvong and Kaneko, 2010), as with other human activities. Nevertheless, despite some empirical evidence for a link between particular aspects such as transport fuel consumption and population density (Newman and Kenworthy, 
1989; Brownstone and Golob, 2009), there are no conclusive findings on the relationship between urban form and overall energy consumption (Mindali et al., 2004; Makido et al., 2012). Research into this relationship is therefore crucial to tackle the current challenge of reducing carbon-based energy and preventing the negative consequences of carbon emissions (Lovelace, 2014; Anderson et al., 2015).

Definitions of urban form vary in the literature (Schwarz, 2010; Tsai, 2005). Initially, urban form referred to the physical characteristics composing the built environment, including shape, size, density and arrangement of settlements (Clifton et al., 2008; Williams, 2014). Many authors still use these landscape metrics (Huang et al., 2007; Schneider and Woodcock, 2008; Bhatta, 2010), as they cover the analysis of land use change and quantify urban sprawl (Kasanko et al., 2006; Dieleman and Wegener, 2004). However, since urban form has a diverse range of influences (Schwarz, 2010; Batty and Longley, 1994), many studies also include socio-economic indicators (Kasanko et al., 2006; Tsai, 2005; Frenkel and Ashkenazi, 2008) when defining urban form. These socio-economic metrics include social processes in the analysis of urban form (Lima, 2001), representing the built environment by the distribution of socio-economic variables (Schirmer and Axhausen, 2015). This attempts to assess how human behaviour varies in space (Schirmer and Axhausen, 2015; Gil, 2016) and the impact of human behaviour on urban form. For example, how travel behaviour is influenced by population density.

Urban form can be studied at different scales - from regional to urban and street level - and influences social, environmental, economic and technological developments. Considering this premise and that no universal urban form definition exists, in this paper a few variables are selected based on both landscape metrics and socio-economic indicators to understand their relationship with energy consumption. Apart from avoiding a firm definition of urban form, LSOA units are used as the basis for analysis. The selection of variables was based on previous research (Schwarz, 2010; Huang et al., 2007; Bhatta, 2010; Kasanko et al., 2006; Schneider and Woodcock, 2008; Tsai, 2005) and other related studies.

\section{Scaling Laws}

Cities and other human settlements are complex systems that result from intricate demographic, social, economic, cultural, geographical and political dynamics and constraints (Hillier and Vaughan, 2007; Arcaute et al., 2015; Wang, 2015). Many theories and research have tried to understand those dynamics and the complexity of the cities (Portugali et al., 2012; Jiang et al., 2012; Samet, 2013). In this paper, only the relationship between energy and selected urban attributes is analysed. This relationship is investigated by looking for scaling-law dependencies of the energy variable on urban form variables in the two datasets. If any correlation exists then the scaling exponent is computed, along with the goodness of fit, as described below. 
Scaling law relationships have been investigated at a city scale by some researchers, comparing urban areas against each other to understand how the increases and decreases of socio-economic characteristics (and other factors) correspond with city population (or size) (Arcaute et al., 2015; Bettencourt, 2013). The basic scaling technique employs an analogy of Kleiber's allometric scaling of metabolic rate (Kleiber, 1947), relating to the variation of urban characteristics to population (Cottineau et al., 2016), using a power-law relationship, determined by:

$$
Y=t P^{\beta}
$$

where $Y$ is the urban characteristic, $t$ is a (time dependent) constant, $P$ is the total population of a city and $\beta$ is the scaling exponent.

In this paper, $Y$ is replaced by energy consumption and $P$ by the selected urban form characteristics to identify their corresponding scaling exponent $\beta$. Considering possible values for $\beta$, three scaling regimes are discussed in previous research:

1. the sublinear regime, $\beta<1$, is associated with economies of scale, where increases in population require proportionally less infrastructure, etc.;

2 . the linear regime, $\beta \approx 1$, is associated with human needs and suggesting a constant per capita Y quantity across the city;

3. the superlinear regime, $\beta>1$, is associated with increased productivity per capita resulting from more social interactions (Bettencourt, 2013; Cottineau et al., 2016).

Some of the literature dealing with scaling laws in cities shows contrasting results: there is some disagreement of which urban features do indeed follow these laws (if any) and which regime they belong, if so (Pumain et al., 2006; Bettencourt, 2013; Louf and Barthelemy, 2014b; Oliveira et al., 2014; Arcaute et al., 2015). The lack of consensus is related to the definition of a city, as selecting different boundaries give different scaling relationships (Cottineau et al., 2016). In the current research this problem is avoided by not pre-defining what constitutes a city and its boundaries, instead using LSOA units as the basis of analysis on both the energy metric and the selected urban form variables. These units are used in the analysis to understand the increases and decreases of energy consumption in relation to urban attributes.

\section{Methodology}

The data at different scales was unified to LSOA geographic level before analyzing using the methodology outlined below. The use of LSOA units enables a more fine-grain detailed analysis that may provide a more detailed understanding of energy use to policy-makers seeking to reduce or mitigate $\mathrm{CO}_{2}$ emissions. The method of analysis was split in two main parts: i) 
estimating the operational energy consumption of buildings and commute transport based on our simple energy use metric; ii) understanding the relationship between that energy and selected urban characteristics based on urban form. This second part of the methodology is broken into two components: i) selection of urban attributes or characteristics; ii) calculation of scaling exponents, as well as strength of correlation, between energy and these urban features. A description of each part and component follows.

\section{The Energy Use Metric}

A simple metric was used to measure the energy use of both buildings and transport, which was introduced in a previous work (Osório et al., 2015, 2016). The metric includes only the operational energy of buildings - directly linked to short-term urban features that interact with transport - and the commute transport carbon footprint, converted to energy use. Operational energy and commute transport energy are investigated as these are variables over which local authorities and urban planners are expected to have the most control. Essentially, the approach is built on the fundamental relationship:

$$
E=B+T
$$

where $E$ is the total energy consumption, $B$ is the buildings energy consumption and $T$ is the transport carbon footprint.

Due to the infeasibility of collecting the actual energy values of all buildings and vehicles, energy consumption must be estimated from statistical data. The estimate of energy consumption of buildings $B$ was based on subregional energy utility data (DECC, 2016) and the commute transport carbon footprint $T$ derived from an Origin-Destination (OD) matrix table of commute trips (O'Brien and UCL CASA, 2014). Both datasets are freely available from official UK government sources - the Department of Energy \& Climate Change (DECC) and the Office for National Statistics (ONS), respectively -, which are perceived as being both reliable and accessible data sources for end users of the research.

DECC's datasets on the operational energy consumption of buildings including the consumption of electricity, gas, coal and other products by both residential and non-residential buildings - are published in $k W h$, based on meter readings and hence are point-of-use energy figures (DECC, 2016). Since the energy metric used herein includes an estimate of both buildings and commute transport, the common SI unit of measurement the megajoule $(M J)$ was used. The conversion from $k W h$ to $M J$ was based on the following rate:

$$
1 k W h=3.6 M J
$$

Obtaining the carbon footprint of commuter transport in terms of energy consumption in $M J$ requires several steps. Both road and rail transport were included in the analysis, with road transport including that of a car, motorcycle 
and bus. The ONS's Origin-Destination (OD) table of commute trips (which can be visualized in (O'Brien and UCL CASA, 2014)) gives figures for the number of people undertaking journeys for commuting by each mode of transport in a given day. Therefore, the calculation of the road transport carbon footprint for any given mode of transport can be obtained from:

$$
R o=L D_{O D} C_{f} P W_{d} 2
$$

where $L$ is the number of litres of fuel consumed by $\mathrm{km}, D_{O D}$ is the Road Distance between an $O D$ pair, $C_{f}$ is the fuel conversion factor for each mode of transport, $P$ is the number of people commuting for each method of travel, and $W_{d}$ is the number of working days in UK in a given year; the factor of 2 is used to include the return journey of commuters each day.

The fuel conversion factors for each mode of transport are based on recognized conversion tables (MacKay, 2008), giving the values of commute transport consumption in $k W h$, which is then converted to $M J$ using factor (3). It should be noted that, although some commute travels are made outside of the normal working week, it has been assumed that the contribution from this is small and thus $W_{d}$ was used. The total road distance (in $\mathrm{km}$ ) between each $O D$ pair was obtained using a scripted interface to Google Maps on-line IDE tool (Google, 2016).

Equation (2) was then applied to aggregate the data at the Lower layer Super Output Area (LSOA) geographic level, which are statistical-purpose geographical units delimited by an area with 1000 to 3000 permanent residents and 400 to 1200 households. An LSOA unit is used here as a large scale unit, allowing the urban areas to be split into fine-grained local regions while at the same time containing enough individuals to be statistically meaningful. This large scale allows a more detailed analysis of the energy consumption patterns and associated carbon emissions.

\section{Urban Form Metrics}

As mentioned in "Urban Form" subsection, although definitions of urban form vary in the literature (Schwarz, 2010; Tsai, 2005), both landscape metrics and socio-economic indicators were considered in the selection of urban characteristics to search for correlations with energy consumption. Landscape metrics enable the understanding of land use change and quantification of urban sprawl (Kasanko et al., 2006; Dieleman and Wegener, 2004), whereas socio-economic indicators include social processes and spatial behaviour in the analysis (Lima, 2001; Schirmer and Axhausen, 2015; Gil, 2016) Several urban form definitions were considered, based on previous studies (Schwarz, 2010; Huang et al., 2007; Bhatta, 2010; Kasanko et al., 2006; Schneider and Woodcock, 2008; Tsai, 2005). The following measures were selected (Table 1), taking into consideration previous research, data availability at the scale of analysis and significance to the study of energy consumption: 
Table 1. Selected Urban Form Measures

\begin{tabular}{|l|l|}
\hline Landscape metrics & Socio-economic indicators \\
\hline Surface area $\left(\mathrm{km}^{2}\right)$ & Density of household spaces $\left(\mathrm{hh} / \mathrm{km}^{2}\right)$ \\
\hline Area of domestic buildings $\left(\mathrm{m}^{2}\right)$ & Population density $\left(\mathrm{prs} . / \mathrm{km}^{2}\right)$ \\
\hline
\end{tabular}

\section{Definitions of Selected Urban Form Metrics}

From the selected features, surface area refers to the total extent of each LSOA unit; area of domestic buildings represents the surface area covered by residential buildings; density of household spaces is related to the density of housing, corresponding to the number of household spaces per $\mathrm{km}^{2}$; and population density describes the number of permanent residents per unit surface area.

Socio-economic measures were obtained from Census statistics (ONS, 2011) and landscape measures from land use datasets (Ordnance Survey, 2016), seeking to account for the complexity, compactness, heterogeneity, density and centrality dimensions of urban form (Herold et al., 2002; Clifton et al., 2008; Schwarz, 2010). However, the methods used here allow the addition of other variables to the analysis if the data is available and results relevant to understanding the relationship between energy consumption and urban form characteristics.

\section{Obtaining Correlations and Scaling Law Relationships}

To understand the relationship between operational energy consumption and urban form characteristics, the existence of any linear or non-linear scaling relationships between the two datasets were investigated.

Scaling laws were used to understand the non-linear relationship between energy and urban attributes, as mentioned in subsection "Scaling Laws". The effects of urban form on energy use have already been examined before (Holden and Norland, 2005; Ewing and Rong, 2008; Tso and Guan, 2014), but at a smaller scale and with less detail than the analysis presented in this paper. The use of LSOA units avoids the complicating need to define city boundaries, but also permits understanding of the internal dynamics of cities and urban areas, rather than cities as a whole. Furthermore, the current analysis focuses on the relationship between energy and different urban form characteristics, not only population size considered by most other research on scaling laws.

To obtain the scaling law exponents of any power-law relationship in the data, the logarithm is taken of both sides of Equation (1), giving the linear relationship:

$$
\log (Y)=\beta \log (P)+C
$$

where $Y$ is the energy consumption indicator, $P$ is the urban form characteristic and $\beta$ is the scaling exponent $(C=\log (t)$ is a constant offset). 
A linear fit was then used to find the gradient $\beta$ and determine the scaling relationship between the two variables.

The Pearson product-moment correlation was then used for the analysis due to its consistency as a powerful and parametric test (Walker, 2010). The magnitudes of the Pearson's correlation coefficients are between 0 and 1 , showing weak to strong linear relationship. Previous studies (Newman and Kenworthy, 1989; Handy et al., 2005; Mindali et al., 2004; Huang et al., 2008) use correlation to explain the relationship between energy consumption and different urban form indicators, but the number of variables taken into account is usually small (Nichols and Kockelman, 2015) and most approaches focus on entire cities (Newman and Kenworthy, 1989) and not large scale analyses, as the present paper proposes.

Using this methodology, the influence of urban form on energy use was analyzed by generating both scaling laws relationships and their associated strength of correlation.

\section{Results and Discussion}

The results presented here consist of: i) application of the energy use metric to obtain the total operational energy consumption per LSOA unit; ii) determination of the nonlinear correlation between urban characteristics and energy consumption and the value of the scaling exponents.

\section{Energy Consumption}

Figure 1 shows the per capita operational energy consumption, applying the energy use metric (given by Equation (2)) and was generated using a Geographical Information System (GIS) framework.

The results demonstrate a notable similarity between total energy (a) and buildings alone (b). This is not unexpected since the average contribution of buildings to total energy consumption is about 90\%. The low commute transport energy of Greater London (Figure 1(c)) - which has better public transport than the rest of the country - reveals clearly how important this is to reduce commute energy consumption. In any case, lower per capita consumption values are found in major cities and urbanized areas (with the exception of natural-protection areas such as the ones found in the South West region: e.g. Dartmoor National Park in Cornwall and the Cranborne Chase chalk plateau in the counties of Dorset, Hampshire and Wiltshire). Such aspects corroborate the literature claiming that higher population densities found in urban areas have better energy efficiency, and therefore lower energy consumption (Newman and Kenworthy, 1989; Næss, 2012). Because of that, the relationship between population density and commute transport energy consumption is clearer when comparing Figures 1 (c) and (d): the most densely populated areas display lower per capita consumption. This suggests per capita energy consumption as a satisfactory measure to compare against urban form 
measures (in this case, the urban system in England). The analysis that follows seeks to confirm and further interrogate these findings to set the ground for a theoretical framework that can be used to guide better strategies to reduce energy use and related carbon emissions.

Scaling and Correlation between Energy Consumption and Urban Form Characteristics

The scaling exponent $\beta$ values (Eqn. (1)), found by comparing the variation of the operational energy consumption with different urban form characteristics are given in the different graphs and tables below. All the following results are presented on a log-log scale so that a power-law scaling appears as a linear relationship (Eqn. (5)), allowing simple linear regression techniques to be used to both fit the exponent and obtain correlation strengths.

\section{Unsuitable Measures of Urban Form}

A comparison between the total energy $E$ against one measure of urban form - the footprint area of domestic buildings for each LSOA - is shown in Figure 2(a) for all regions in England. The Figure shows that no clear relationship is observable, indicating a negligible correlation between the two variables. A large variation of values is perceived, despite some noticeable differences between regions. This is shown more clearly in the density plot (Figure 2(b)), which demonstrates that most of the values are clustered in a cloud of points between about 10,000 and 100,000 square meters of buildings per LSOA. Consequently, the lack of correlation suggests that the area of domestic buildings should not be used as an indicator to define urban form when studying relationships between urban form and energy consumption. However, since LSOA units are composed of a limited number of residents and households, and thus associated only with the operational energy consumption of domestic buildings, further research is needed to investigate if relationships may be distinguished at different scales of analysis.

\section{$\underline{\text { Evidence for Scaling between Urban Form and Energy Use }}$}

The relationship between energy consumption and population density is shown in Figure 3. Although a wide spread of values is still evident, a clearer relationship is observed between these two variables than the previous case. The relationship between population density and commute transport energy is stronger than with the total operational energy consumption. However, a clear negative correlation trend between population density and the total energy consumption can be seen, contained within a bounded "triangular" region. Moreover, the Greater London region can be distinguished in the overall plot, indicating the need to separate out the data into distinct regions for further analysis, rather than considering urban England as a whole ("Correlation Strengths" subsection). 
Figure 1. Energy Consumption by LSOA per Capita in England: (a) Total, (b) Buildings and (c) Commute Transport; (d) Population Density. [Source: ONS, DataShine (data); Ordnance Survey (Cartography)]

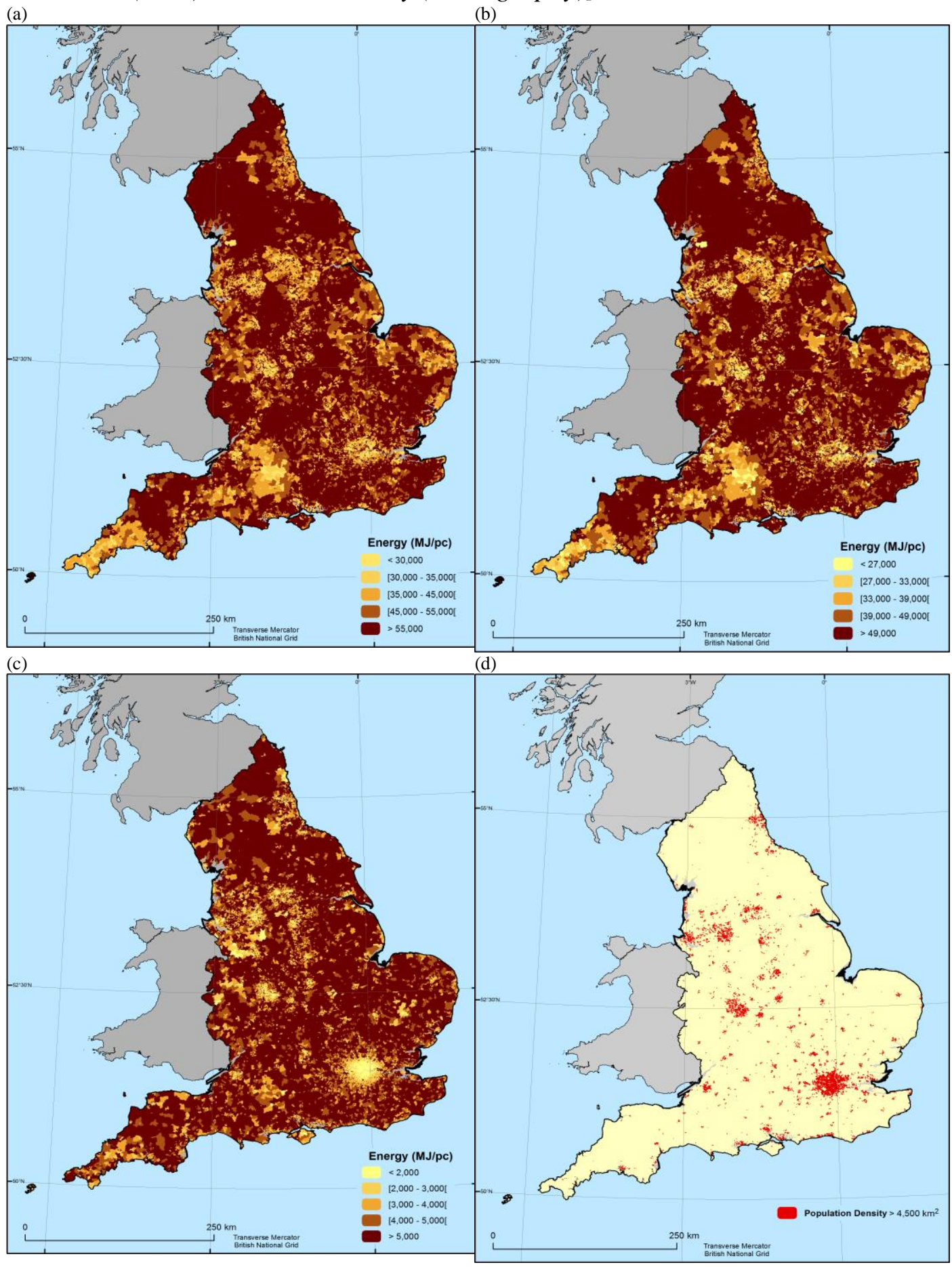

The stronger relationship between population density and commute transport energy (Figure 3(b)) can be observed by the lower spread of values around the negative trend. This is in agreement with the general literature 
(Newman and Kenworthy, 1989; Su, 2011; Næss, 2012) that describes a negative correlation between urban density and fuel consumption.

Figure 2. Relationship between Total Energy Consumption and Domestic Buildings Area in England: (a) Region Plot, (b) Density Plot

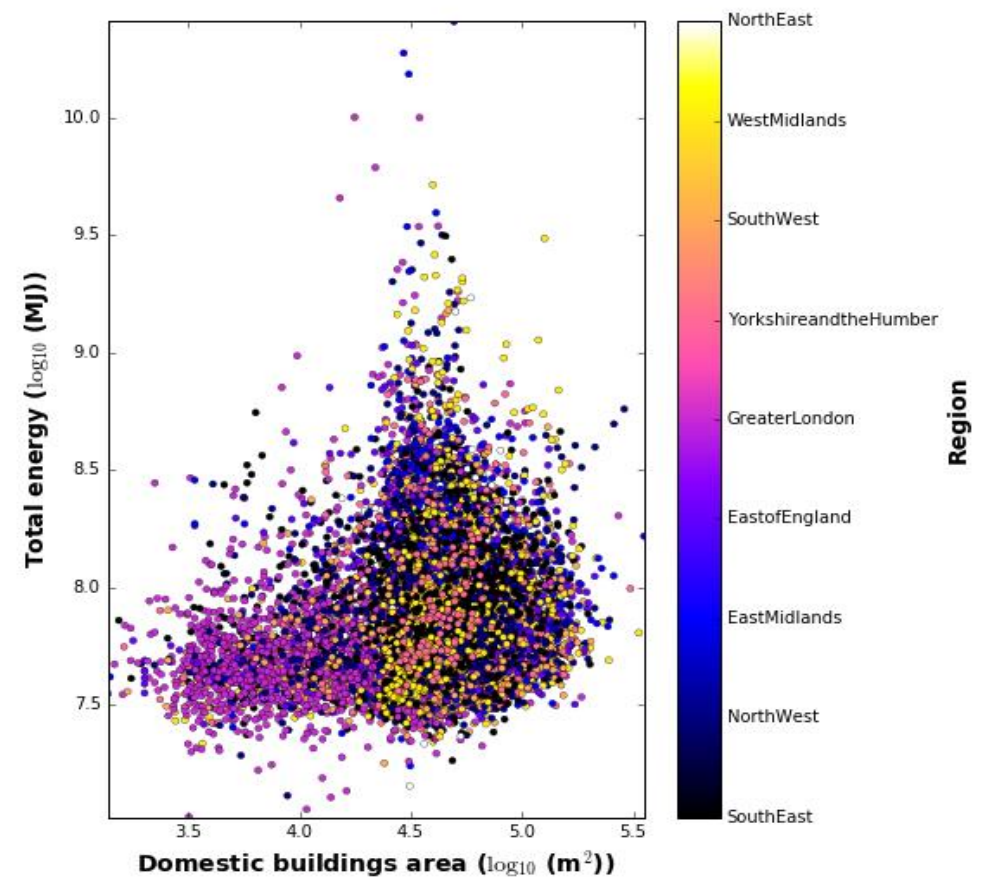

(a)

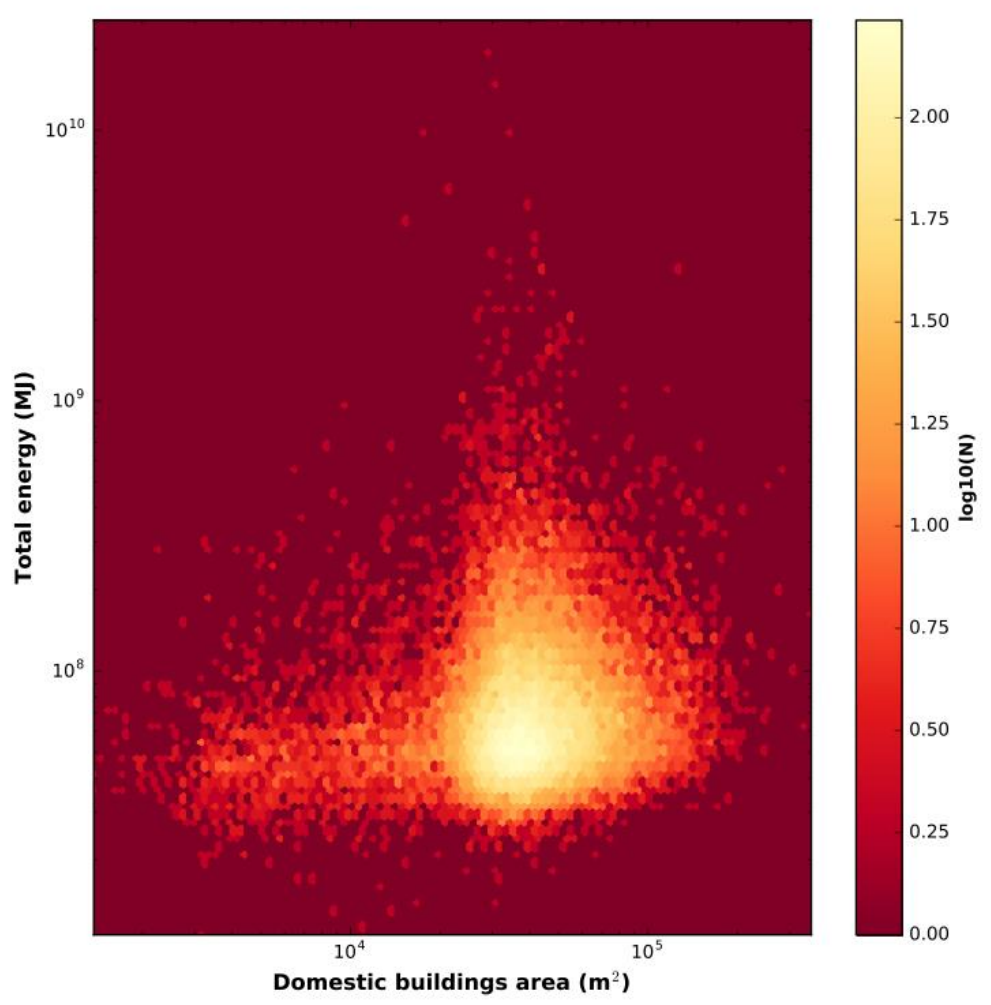

(b) 
Figure 3. Relationship between Energy Consumption and Population Density in England: (a) Total Energy E, (b) Commute Transport Energy T

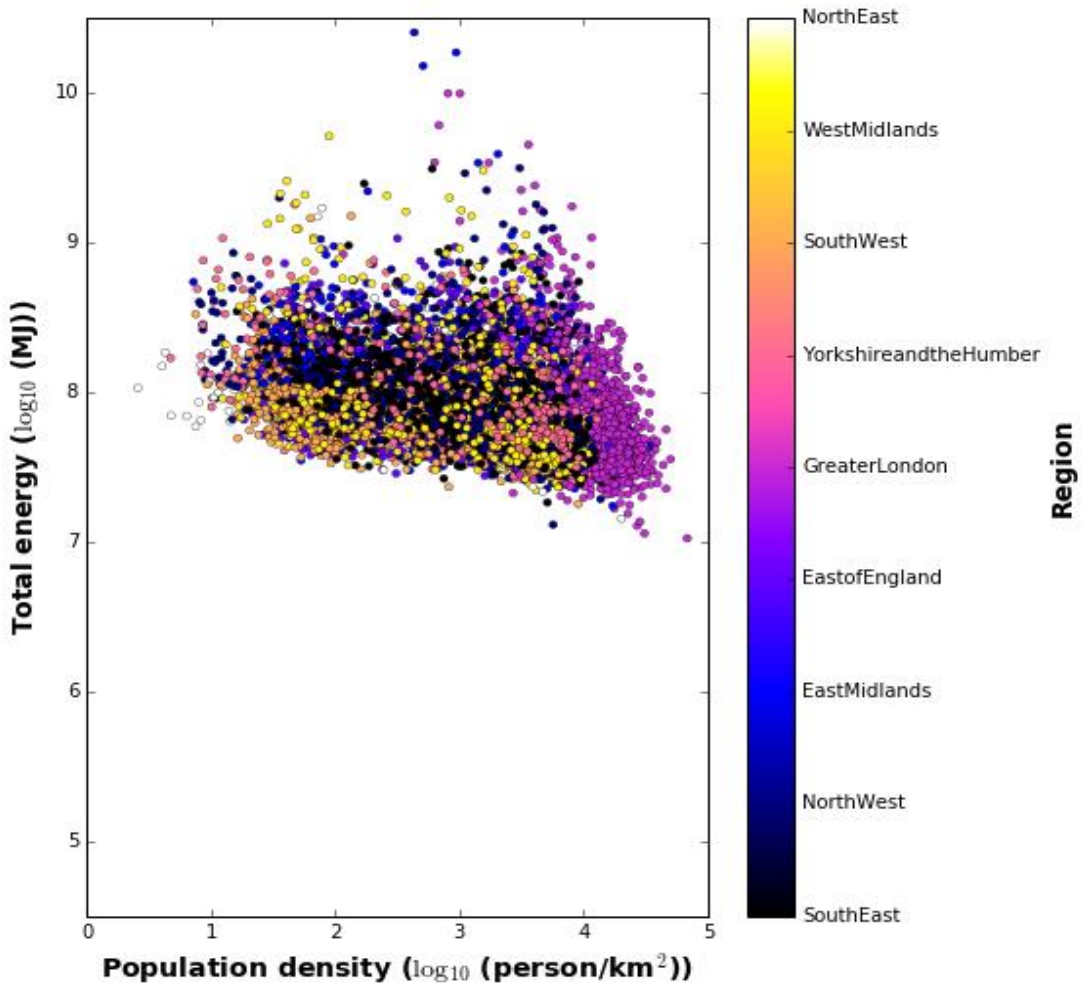

(a)

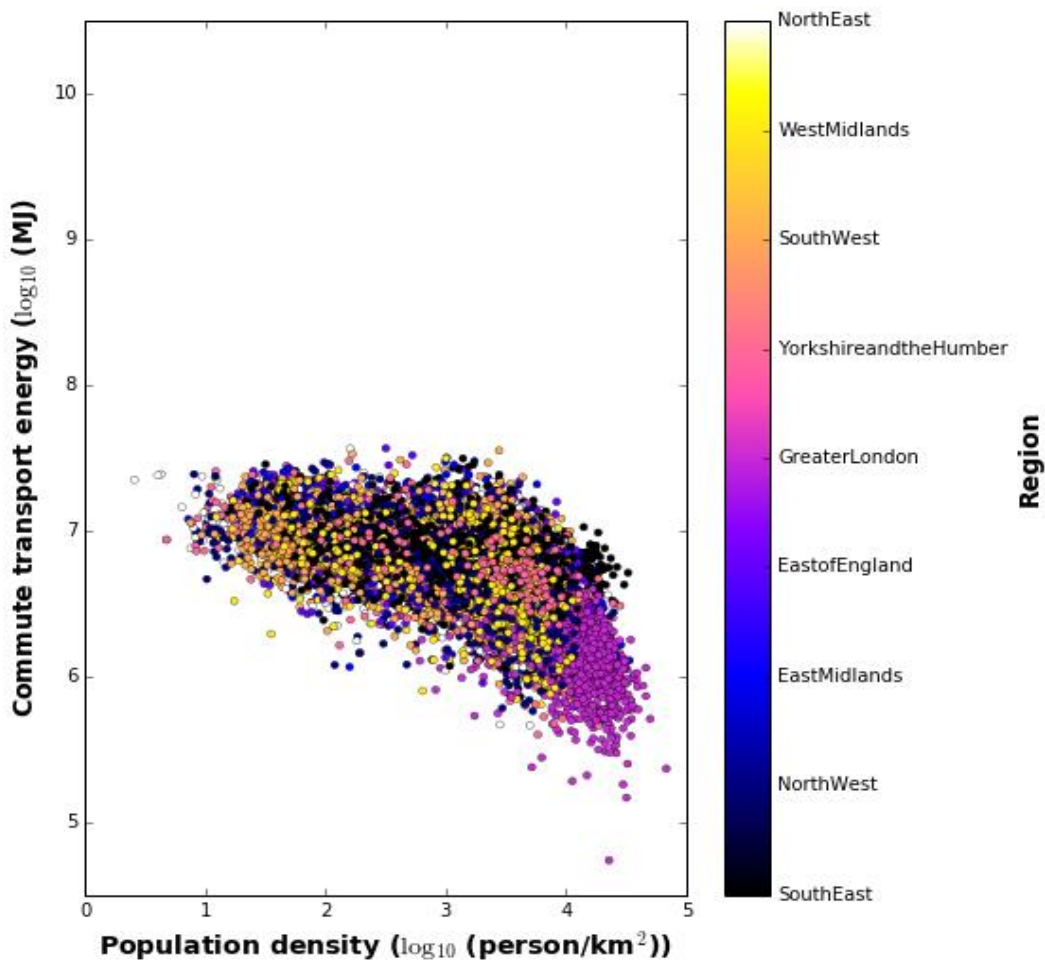

(b) 
Figure 4. Density Plots of the Relationship between Energy Consumption and Density Measures in England: (a) Population Density, (b) Density of Household Spaces

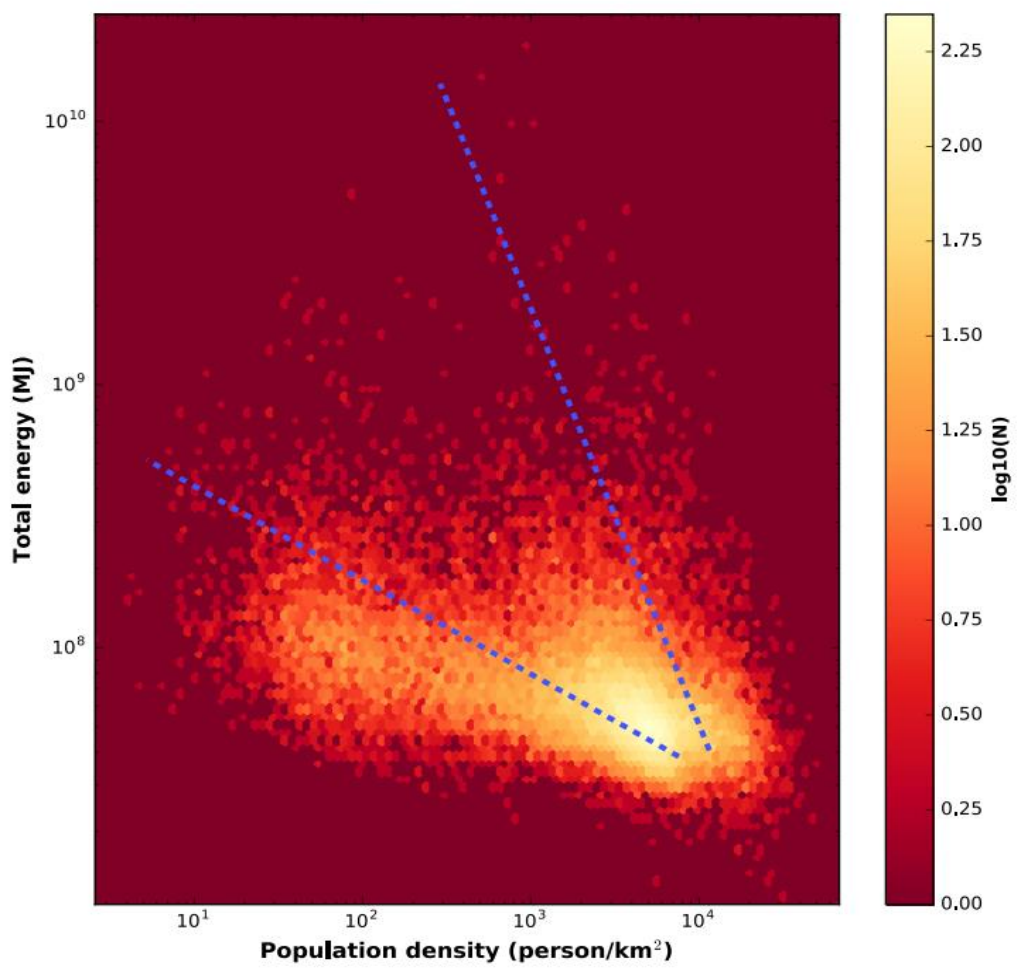

(a)

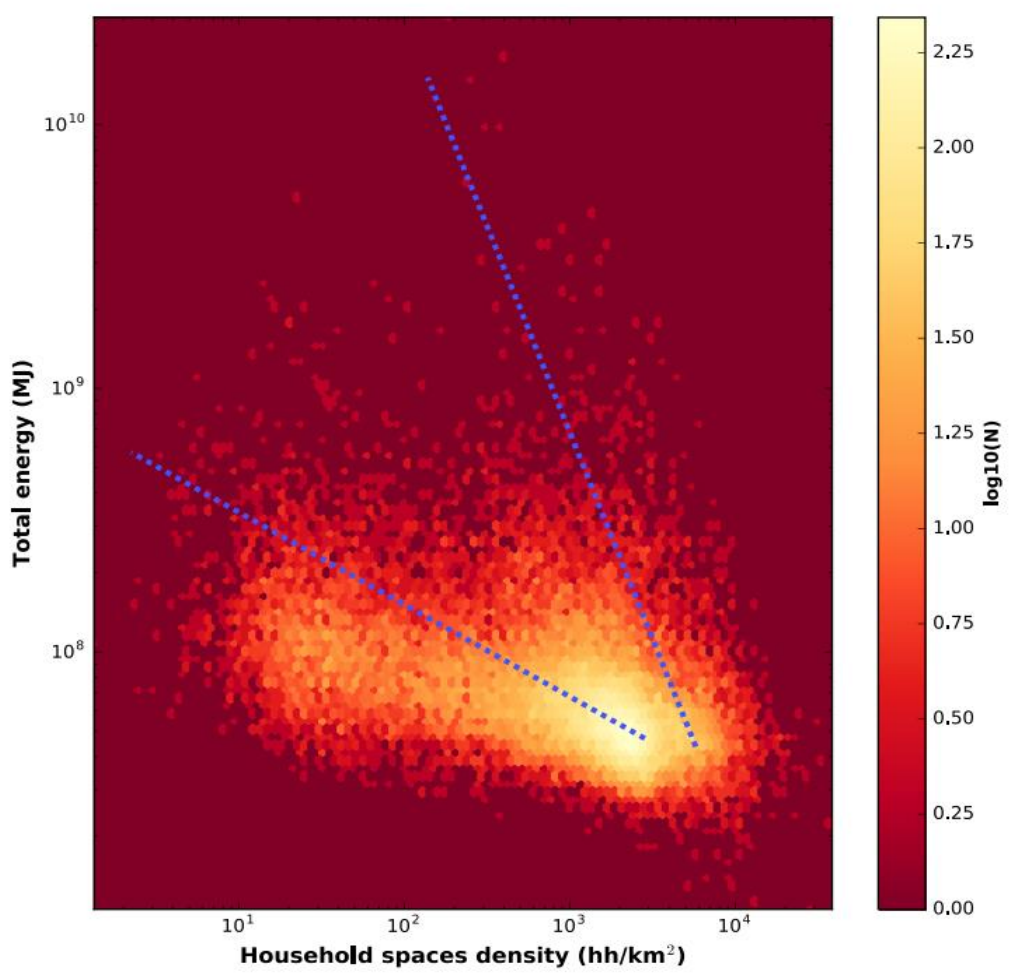

(b) 
Deeper insight into the results such as those shown in Figure 3(a) can be obtained by looking at density plots, as demonstrated in Figure 4. A notable characteristic is the similarity between two different urban density measures: population density and household spaces density. This indicates that either variable could be used as a proxy for the other in the event of data unavailability.

The density plots of Figure 4 also show two distinct trends (indicated by blue dotted lines) for the relationship between total energy consumption and the density variables. These distinct trends indicate that different geographical characteristics of the LSOA units, possibly related to physical and socioeconomic factors, have different effects on energy efficiency. This suggests further research to obtain a more detailed explanation: for example, comparing several geographical characteristics of the LSOAs associated with the two trends to identify differences.

One potential hypothesis would be that each trend describes either the buildings energy consumption or commute transport energy, respectively. Therefore, energy consumption by transport and buildings was split by the regions and Local Authorities (LA) of England in the following results.

\section{Correlation Strengths}

The analysis of Figure 5 shows the relationship between population density and energy consumption for the Greater London region, split into that for buildings and transport. It can be seen that commute transport energy, shown in (b), depends more strongly on population density than that of buildings (a). However, the results do not confirm the hypothesis that this explains the different trends in the combined energy data, as the data for buildings still appears to be composed of multiple trends, with the line of the best fit (red line) averaging over a wide spread of values. This is confirmed by the values for correlation coefficients of -0.325 for buildings and -0.652 for transport.

Another important point is that the relatively small proportion of transport $-10 \%$ on average - in the total energy consumption may mask its influence in the grand total. The large area of the Greater London region also makes it too diverse and thus less uniform to usefully analyze either the total energy consumption or individually by buildings or commute transport.

The problem of the overwhelming scale of London can be avoided by considering smaller, more distinct city regions such as Birmingham. Figure 6 depicts the relationship between population density and energy consumption for Birmingham at Local Authority level. As with the previous results, a correlation can be observed between both sets of energy ( $B$ and $T)$, although the correlation value for transport $(-0.603)$ is still slightly larger than the coefficient for buildings (-0.545). A similar variation around the line of best fit to the previous case is observed when analyzing buildings energy alone, with the graph for the energy consumption of buildings (Figure 6(a)) displaying two trends (to the low density end). 
Figure 5. Relationship between Energy Consumption and Population Density for Greater London: (a) Buildings Energy, (b) Commute Transport Energy

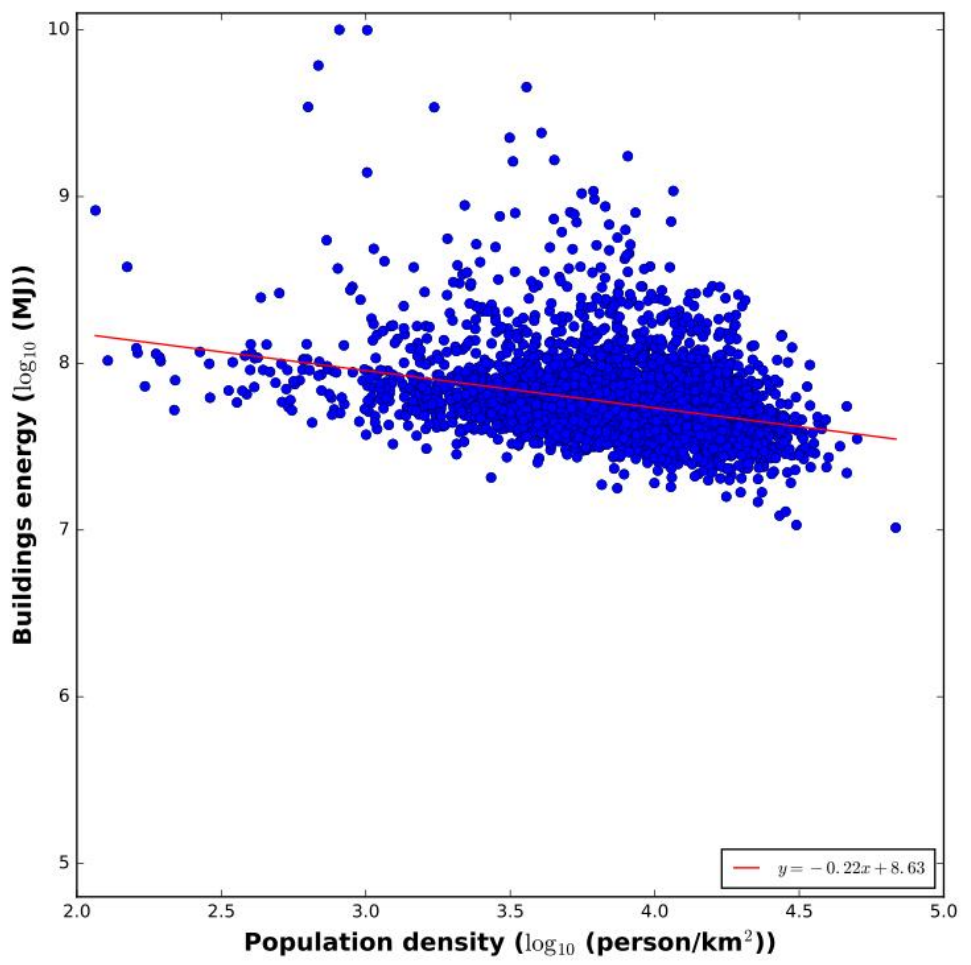

(a)

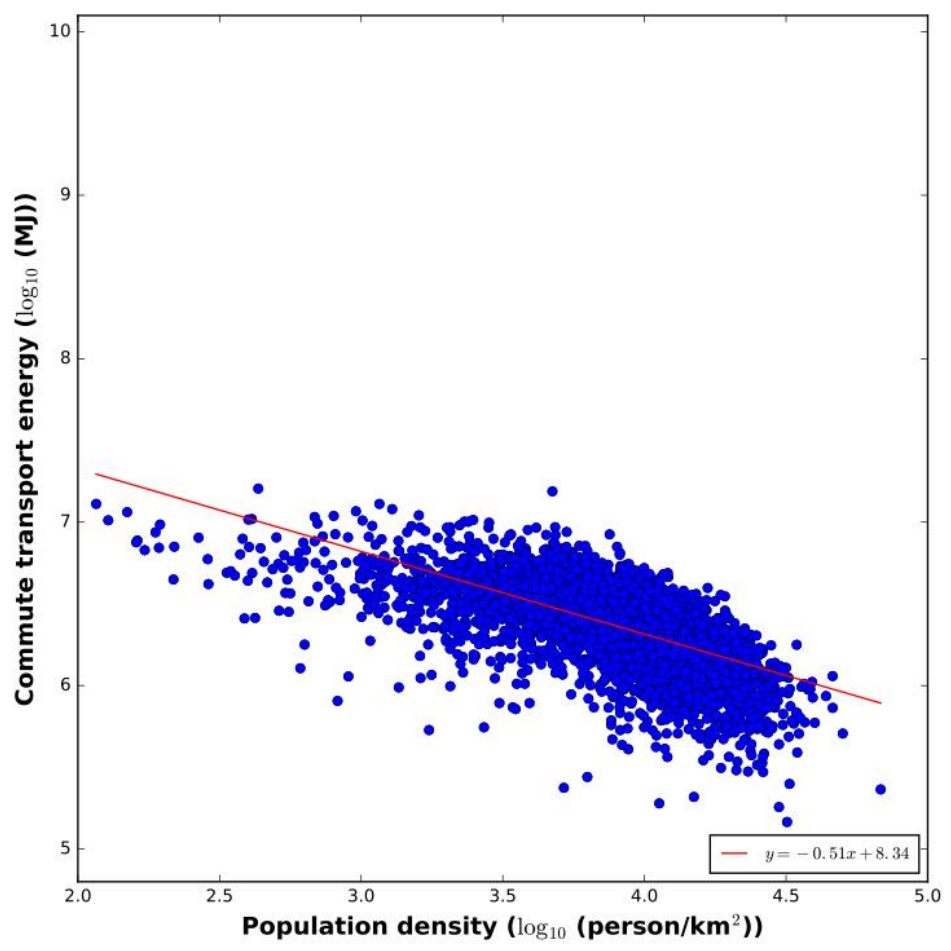

(b) 
Figure 6. Relationship between Energy Consumption and Population Density for Birmingham: (a) Buildings Energy, (b) Transport Energy

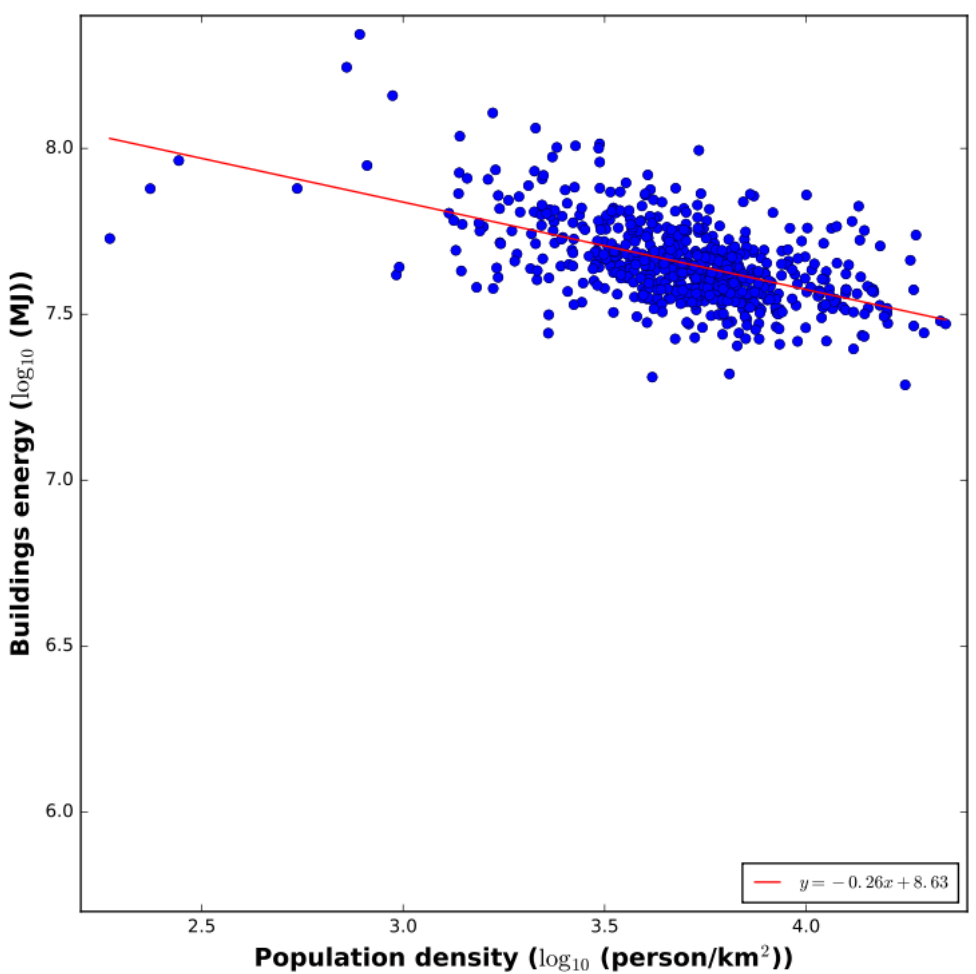

(a)

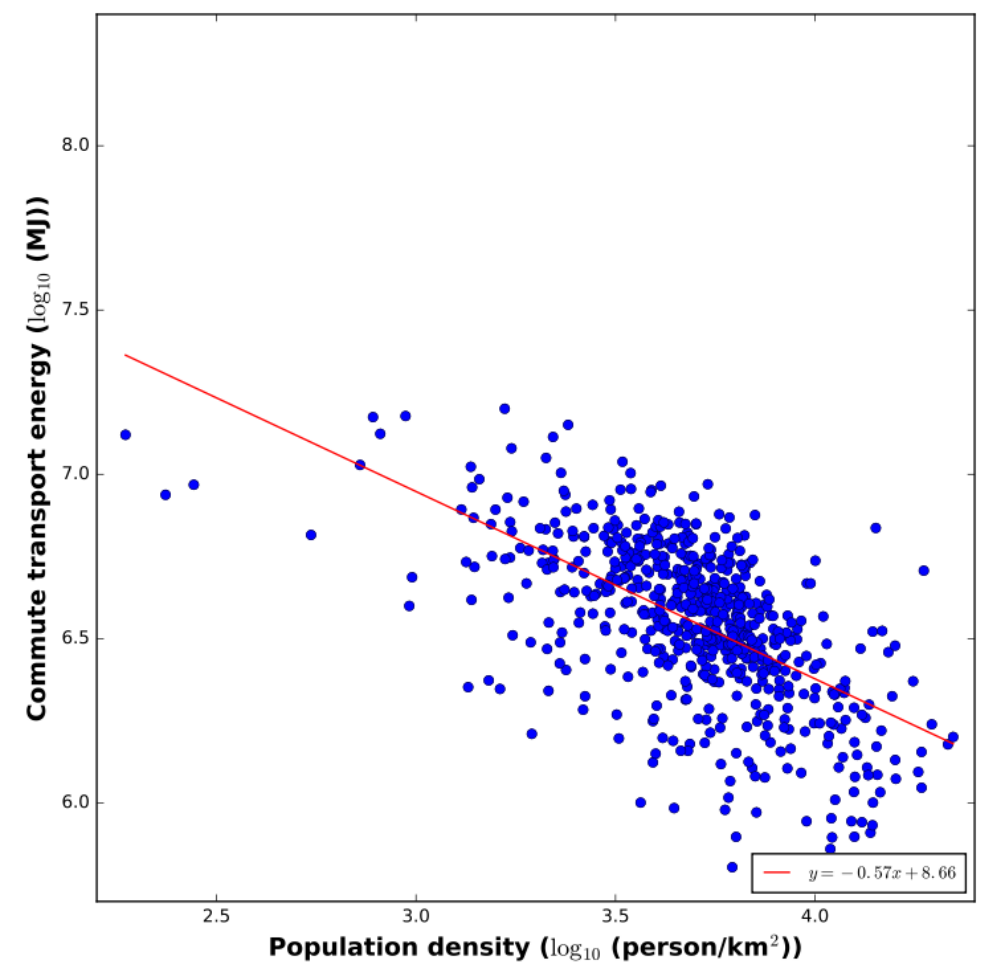

(b) 
Table 2 presents a summary of the correlation values between energy consumption and selected urban form characteristics. This shows that the strength of correlation between energy consumption and urban form attributes varies, but essentially density indicators have a moderate strength of association with energy consumption. The main exception is related to the area of domestic buildings, showing a small correlation value. The remaining density measures display some significant correlation coefficients. Another example is the use of surface area as a density measure, where its correlation with energy consumption is also moderate, given by a significant value in Table 2.

Table 2. Correlation coefficients values for different urban form measures

\begin{tabular}{|l|l|l|}
\hline $\begin{array}{l}\text { Energy } \\
\text { consumption }(\mathbf{M J})\end{array}$ & Urban form & Coefficient \\
\hline Total & Population density $\left(\mathrm{prs} . / \mathrm{km}^{2}\right)$ & -0.483 \\
\hline Buildings & Population density $\left(\mathrm{prs} . / \mathrm{km}^{2}\right)$ & -0.455 \\
\hline Transport & Population density $\left(\mathrm{prs} . / \mathrm{km}^{2}\right)$ & -0.617 \\
\hline Total & Household spaces density $\left(\mathrm{hh} / \mathrm{km}^{2}\right)$ & -0.472 \\
\hline Total & Area of domestic buildings $\left(\mathrm{m}^{2}\right)$ & 0.126 \\
\hline Total & Surface area $\left(\mathrm{km}^{2}\right)$ & 0.514 \\
\hline
\end{tabular}

This demonstrates the importance of density indicators in assessing and estimating energy consumption in urban areas. These findings indicate that any of those density variables may be used to define urban form and to study their relationship with energy consumption, with no need to employ more than one measure and duplicate information.

\section{$\underline{\text { Scaling Analysis }}$}

The results for the scaling relationship between energy consumption and the selected urban characteristics show that urban energy follows an economy of scale, i.e. it demonstrates sublinear scaling behavior (scaling exponent $\beta<$ 1). This indicates that increases in population have a smaller effect on energy consumption, in agreement with some previous research arguing that higher density areas use less energy and therefore demonstrate better energy efficiency (Newman and Kenworthy, 1989; Næss, 2012). Figure 7 shows the scaling exponent values and confidence intervals (given by the standard deviation of the fit) of total energy consumption in association with population density for various city LA regions. Each of these demonstrates sublinear scaling behavior, although different values are observed for the different cities. 
Figure 7. Scaling Exponent Values and Respective Standard Deviation in the Relationship between Total Energy Consumption and Population Density for selected locations

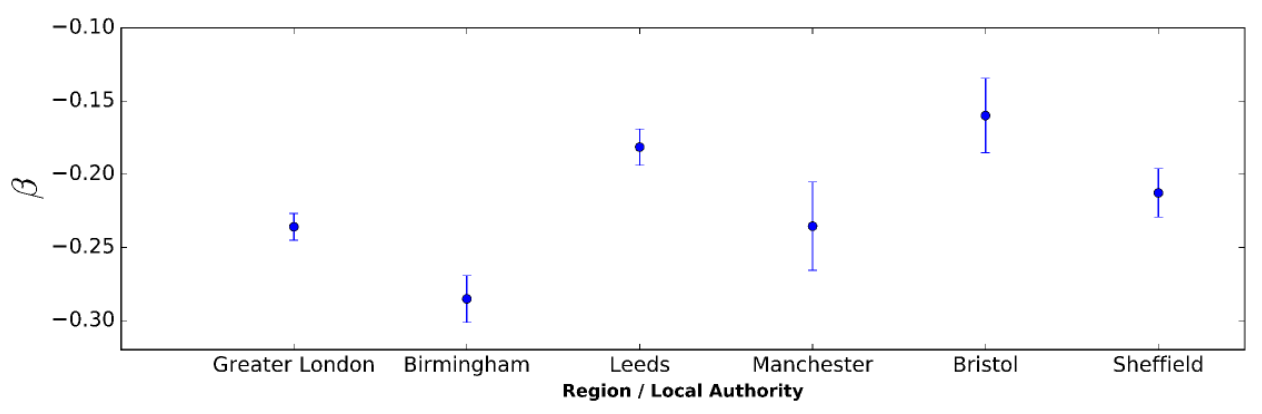

When analyzed by decomposing the different components of energy consumption - total $E$, buildings $B$ and commute transport $T$-, a difference in the scaling values for the LA regions is observed. Table 3 displays this variability, showing the scaling exponent values for the three sets of energy consumption. It shows that the exponent values related to transport are usually higher than that for buildings, with some exceptions. Manchester and Bristol are two cases that demonstrate this, with the scaling exponent value for the energy consumption of buildings being larger than that for commute transport. Therefore, there is not a specific trend: both big and smaller cities can have higher and lower scaling exponent values, depending on characteristics yet to be determined.

Table 3. Power-law-exponents of energy consumption to population density

\begin{tabular}{|l|l|l|l|}
\hline Region / Local Authority & Total & Buildings & Transport \\
\hline Greater London & -0.24 & -0.22 & -0.51 \\
\hline Birmingham & -0.29 & -0.26 & -0.57 \\
\hline Leeds & -0.18 & -0.17 & -0.31 \\
\hline Manchester & -0.24 & -0.24 & -0.21 \\
\hline Bristol & -0.16 & -0.16 & -0.12 \\
\hline Sheffield & -0.21 & -0.20 & -0.29 \\
\hline
\end{tabular}

Furthermore, while the urban characteristics examined in this paper follow sublinear behaviour, which is in agreement with some literature (Rybski et al., 2016; Fragkias et al., 2013), other studies suggested a superlinear relationship between population and $\mathrm{CO}_{2}$ emissions related to transport (Oliveira et al., 2014; Louf and Barthelemy, 2014a). Further investigation covering more urban characteristics is required to achieve more definitive or better conclusions, but the methods presented in the current work provide a clear and systematic way of doing this, using available and reliable data, using a scale that does not require predefining the boundaries of a city. 


\section{Limitations of the Work}

It is important to emphasize some limitations of the research. Firstly, the presented results relate only to England and use LSOA units. Due to the similarity of the other parts of the UK in terms of administrative geography, it should be easy to replicate the energy use metric in those regions. The use of the metric in other states or regions will depend of data availability and the adjusting of the data to the administrative subdivision. Secondly, as this research is focused on advising local authorities and city planners about reducing day-to-day energy consumption, only the buildings operational energy and commute trips were included in the energy metric, with other types, such as buildings embodied energy, being excluded. However, the simplicity of the energy metric would allow the addition of that omitted data to the analysis, if that information is accessible, reliable and needed for the research question. Thirdly, the work is the initial use of only four urban form characteristics. The results should be interpreted considering that they may not tell the whole story regarding urban systems, but the methodology easily permits comparing different characteristics. Additionally, human perspectives such as well-being are not included in the study, and it should be noted that lower energy consumption may not correlate with better well-being. Although outcomes show that higher density areas demonstrate better energy efficiency, different consequences - social, health, cultural, etc. - that may result from concentration of people can decrease the overall quality of life.

\section{Conclusions and Future Work}

This paper develops an understanding of the relationship between energy consumption and urban form characteristics using an approach based on correlations and scaling laws. To enable this, a simple energy metric was generated to assess the energy consumption in urban areas, which combines the operational energy of both buildings and commute transport in the same approach. The metric also benefits from the use of large geographical scale LSOA units, enabling the identification of more fine-grained patterns of energy consumption. By identifying these patterns, less energy efficient areas can be identified, which may be the target of actions by policy-makers to reduce energy demand. The per capita results show that more densely populated areas - i.e. cities and their surroundings - have better energy efficiency.

Different urban form characteristics were used in the analysis of their relationship with energy consumption. As various urban form definitions exist (Schwarz, 2010; Tsai, 2005), both landscape metrics and socio-economic indicators were taken into account to provide the analysis with a greater scope. The resulting correlations between the datasets showed that some variables such as the land area of domestic buildings demonstrate no real scaling relationship with energy, indicating they may not be ideal to characterize the urban form of cities in this regard. On the other hand, density variables were 
found to have reasonable correlation strength with energy consumption. These findings are in agreement with some recent literature (Boarnet and Crane, 2001; Næss, 2012), suggesting that more densely populated areas demonstrate better energy efficiency. Further analysis revealed stronger correlation values between population density and commute transport energy consumption. Also, in some cases two distinct correlation trends were seen on the density plots.

The analysis of scaling laws in this paper shows that energy consumption demonstrates a sublinear scaling behaviour with respect to the selected urban characteristics, especially population density. This result indicates that energy consumption follows an economy of scale, agreeing with some prior literature (Rybski et al., 2016; Fragkias et al., 2013). However, unlike other studies, the analysis of scaling laws in this paper looks within cities (at the LSOA scale), providing new information about the dynamics of urban areas.

The demonstration of economy of scale, as well as the stronger correlation between density measures and energy consumption, suggests that better energy efficiency is found in higher population density areas. These results reinforce previous results, but also allow investigation into the internal dynamics of cities due to the large scale of analysis used, thus contributing to new knowledge on urban areas, their changes and developments.

The methodology and results of this study open the way for future research. The perceived differences of scaling exponent values between buildings and transport energy consumption, as well as among the several regions and local authorities, can be analyzed considering the different urban characteristics of the LSOAs. These urban attributes may also be an explanation for the two correlation trends seen in some cases (Fig. 4). Expanding the number of urban form indicators in new research will provide new insights into the internal dynamics of the cities. Ultimately, the findings in this paper provide a way forward for researchers, urban policy-makers and planners seeking to design strategies to cut energy consumption and related carbon emissions.

\section{References}

Ajanovic, A., Schipper, L., and Haas, R. (2012) The impact of more efficient but larger new passenger cars on energy consumption in EU-15 countries. Energy, 48 (1), 346-355.

Alberti, M. (2005) The effects of urban patterns on ecosystem function. International Regional Science Review, 28 (2), 168-192.

Anderson, J. E., Wulfhorst, G., and Lang, W. (2015) Energy analysis of the built environment - A review and outlook. Renewable and Sustainable Energy Reviews, $44,149-158$.

Arcaute, E., Hatna, E., Ferguson, P., Youn, H., Johansson, A., and Batty, M. (2015) Constructing cities, deconstructing scaling laws. Journal of the Royal Society Interface, 12 (102), 1-8.

Banister, D., Watson, S., and Wood, C. (1997) Sustainable cities: Transport, energy, and urban form. Environment and Planning B, 24, 125-144. 
Barthelemy, M., Bordin, P., Berestycki, H., and Gribaudi, M. (2013) Self-organization versus top-down planning in the evolution of a city. Nature: Scientific Reports, 3.

Batty, M. and Longley, P. A. (1994) Fractal cities: A geometry of form and function. London, UK, Academic Press.

Bettencourt, L. M. (2013) The origins of scaling in cities. Science, 340 (6139), 1438-1441.

Bhatta, B. (2010) Analysis of urban growth and sprawl from remote sensing data. Berlin, Germany, Springer Science \& Business Media.

Boarnet, M. G. and Crane, R. (2001) The influence of land use on travel behavior: Specification and estimation strategies. Transportation Research Part A: Policy and Practice, 35 (9), 823-845.

Brand, C., Tran, M., and Anable, J. (2012) The UK transport carbon model: An integrated life cycle approach to explore low carbon futures. Energy Policy, 41, 107-124.

Brand, C., Anable, J., and Tran, M. (2013) Accelerating the transformation to a low carbon passenger transport system: The role of car purchase taxes, feebates, road taxes and scrappage incentives in the UK. Transportation Research Part A: Policy and Practice, 49, 132-148.

Brownstone, D. and Golob, T. F. (2009) The impact of residential density on vehicle usage and energy consumption. Journal of Urban Economics, 65 (1), 91-98.

Cappiello, A., Chabini, I., Nam, E. K., Lue, A., and Zeid, M. A. (2002) A statistical model of vehicle emissions and fuel consumption. In: $5^{\text {th }}$ International Conference on Intelligent Transportation Systems, September 2002, Singapore. IEEE, pp. 801-809.

Chapman, L. (2007) Transport and climate change: A review. Journal of Transport Geography, 15 (5), 354-367.

Clifton, K., Ewing, R., Knaap, G.-J., and Song, Y. (2008) Quantitative analysis of urban form: A multidisciplinary review. Journal of Urbanism, 1 (1), 17-45.

Cottineau, C., Hatna, E., Arcaute, E., and Batty, M. (2016) Diverse cities or the systematic paradox of urban scaling laws. Computers, Environment and Urban Systems, in press.

Crawley, D. B., Lawrie, L. K., Pedersen, C. O., and Winkelmann, F. C. (2000) EnergyPlus: Energy simulation program. ASHRAE Journal, 42 (4), 49-56.

Creutzig, F., Baiocchi, G., Bierkandt, R., Pichler, P.-P., and Seto, K. C. (2015) Global typology of urban energy use and potentials for an urbanization mitigation wedge. Proceedings of the National Academy of Sciences, 112 (20), 6283-6288.

DECC. (2016) Statistics at Department of Energy \& Climate Change. Available from: http://bit.ly/2fsd4ih [Accessed 11-2016].

Dhakal, S. (2009) Urban energy use and carbon emissions from cities in China and policy implications. Energy Policy, 37 (11), 4208-4219.

Dieleman, F. M., Dijst, M., and Burghouwt, G. (2002) Urban form and travel behaviour: Micro-level household attributes and residential context. Urban Studies, 39 (3), 507-527.

Dieleman, F. M. and Wegener, M. (2004) Compact city and urban sprawl. Built Environment, 30 (4), 308-323.

Ewing, R. H. and Rong, F. (2008) The impact of urban form on US residential energy use. Housing Policy Debate, 19 (1), 1-30.

Feng, Y., Chen, S., and Zhang, L. (2013) System dynamics modeling for urban energy consumption and $\mathrm{CO}_{2}$ emissions: A case study of Beijing, China. Ecological Modelling, 252, 44-52. 
Fonseca, J. A. and Schlueter, A. (2015) Integrated model for characterization of spatiotemporal building energy consumption patterns in neighborhoods and city districts. Applied Energy, 142, 247-265.

Fragkias, M., Lobo, J., Strumsky, D., and Seto, K. C. (2013) Does size matter? Scaling of $\mathrm{CO}_{2}$ emissions and US urban areas. PLoS One, 8 (6), 1-8.

Franc, P. and Sutto, L. (2014) Impact analysis on shipping lines and European ports of a cap-and-trade system on $\mathrm{CO}_{2}$ emissions in maritime transport. Maritime Policy \& Management, 41 (1), 61-78.

Frenkel, A. and Ashkenazi, M. (2008) Measuring urban sprawl: How can we deal with it? Environment and Planning B - Planning and Design, 35 (1), 56-79.

Gerber, M. (2014) EnergyPlus - Energy simulation software. Swenson College of Science and Engineering - University of Minnesota Duluth. Technical report.

Gil, J. A. (2016) Urban Modality: Modelling and evaluating the sustainable mobility of urban areas in the city-region. PhD thesis, TU Delft - Delft University of Technology.

Gilbert, R. and Perl, A. (2013) Transport revolutions: Moving people and freight without oil. Gabriola Island, Canada, New Society Publishers.

Google. (2016) Google Maps. Available from: http://maps.google.co.uk/ [Accessed 11-2016].

Grimm, N. B., Faeth, S. H., Golubiewski, N. E., Redman, C. L., Wu, J., Bai, X., and Briggs, J. M. (2008) Global change and the ecology of cities. Science, 319 (5864), 756-760.

Handy, S., Cao, X., and Mokhtarian, P. (2005) Correlation or causality between the built environment and travel behavior? Evidence from Northern California. Transportation Research Part D: Transport and Environment, 10 (6), 427-444.

Hao, H., Geng, Y., Li, W., and Guo, B. (2015) Energy consumption and GHG emissions from China's freight transport sector: Scenarios through 2050. Energy Policy, 85, 94-101

Heiple, S. and Sailor, D. J. (2008) Using building energy simulation and geospatial modeling techniques to determine high resolution building sector energy consumption profiles. Energy and Buildings, 40 (8), 1426-1436.

Herold, M., Scepan, J., Clarke, K. C., et al. (2002) The use of remote sensing and landscape metrics to describe structures and changes in urban land uses. Environment and Planning A, 34 (8), 1443-1458.

Hickman, R. and Banister, D. (2014) Transport, climate change and the city, volume 7. Routledge.

Hillier, B. and Vaughan, L. (2007) The city as one thing. Progress in Planning, 7 (3), 205-230.

Holden, E. and Norland, I. T. (2005) Three challenges for the compact city as a sustainable urban form: Household consumption of energy and transport in eight residential areas in the greater Oslo region. Urban Studies, 42 (12), 2145-2166.

Howard, B., Parshall, L., Thompson, J., Hammer, S., Dickinson, J., and Modi, V. (2012) Spatial distribution of urban building energy consumption by end use. Energy and Buildings, 45, 141-151.

Huang, J., Lu, X., and Sellers, J. M. (2007) A global comparative analysis of urban form: Applying spatial metrics and remote sensing. Landscape and Urban Planning, 82 (4), 184-197.

Huang, B.-N., Hwang, M.-J., and Yang, C. W. (2008) Causal relationship between energy consumption and GDP growth revisited: A dynamic panel data approach. Ecological Economics, 67 (1), 41-54. 
Jiang, S., Ferreira Jr, J., and Gonzalez, M. C. (2012) Discovering urban spatialtemporal structure from human activity patterns. In: Proceedings of the $18^{\text {th }}$ ACM SIGKDD International Conference, August 2012, Beijing, China. ACM, pp. 95-102.

Kasanko, M., Barredo, J. I., Lavalle, C., McCormick, N., Demicheli, L., Sagris, V., and Brezger, A. (2006) Are European cities becoming dispersed?: A comparative analysis of 15 European urban areas. Landscape and Urban Planning, 77 (1), 111130.

Kleiber, M. (1947) Body size and metabolic rate. Physiological Reviews, 27 (4), 511-541.

Lima, J. J. (2001) Compensatory urban form. In: Space Syntax $3^{\text {rd }}$ International Symposium, May 2001, Atlanta, USA.

Liu, C. and Shen, Q. (2011) An empirical analysis of the influence of urban form on household travel and energy consumption. Computers, Environment and Urban Systems, 35 (5), 347-357.

Louf, R. and Barthelemy, M. (2014a) How congestion shapes cities: From mobility patterns to scaling. Nature: Scientific Reports, 4.

Louf, R. and Barthelemy, M. (2014b) Scaling: Lost in the smog. Environment and Planning B: Planning and Design, 41 (5).

Lovelace, R. (2014) The energy costs of commuting: A spatial microsimulation approach. $\mathrm{PhD}$ thesis, University of Sheffield.

MacKay, D. (2008) Sustainable energy - without the hot air. Cambridge, UK, UIT.

Madlener, R. and Sunak, Y. (2011) Impacts of urbanization on urban structures and energy demand: What can we learn for urban energy planning and urbanization management? Sustainable Cities and Society, 1 (1), 45-53.

Makido, Y., Dhakal, S., and Yamagata, Y. (2012) Relationship between urban form and $\mathrm{CO}_{2}$ emissions: evidence from fifty Japanese cities. Urban Climate, 2, 55-67.

Marcotullio, P. J., Hughes, S., Sarzynski, A., Pincetl, S., Sanchez Peña, L., RomeroLankao, P., Runfola, D., and Seto, K. C. (2014) Urbanization and the carbon cycle: Contributions from social science. Earth's Future, 2 (10), 496-514.

Mindali, O., Raveh, A., and Salomon, I. (2004) Urban density and energy consumption: A new look at old statistics. Transportation Research Part A: Policy and Practice, 38 (2), 143-162.

Næss, P. (2012) Urban form and travel behavior: Experience from a Nordic context. Journal of Transport and Land Use, 5 (2), 21-45.

Newman, P. W. and Kenworthy, J. R. (1989) Gasoline consumption and cities: A comparison of US cities with a global survey. Journal of the American Planning Association, 55 (1), 24-37.

Nichols, B. G. and Kockelman, K. M. (2015) Urban form and life-cycle energy consumption: Case studies at the city scale. Journal of Transport and Land Use, 8 (3), 115-129.

O'Brien, O. and UCL CASA. (2014) Datashine: Travel to work flows. Available from: http://commute.datashine.org.uk [Accessed 11-2016].

Oliveira, E. A., Andrade Jr, J. S., and Makse, H. A. (2014) Large cities are less green. Nature: Scientific Reports, 4.

ONS. (2011) Census data, 2011. Available from: http://bit.ly/2fsjDkI [Accessed 112016].

Ordnance Survey. (2016) OS MasterMap Topography Layer [GML geospatial data]. Available from: http://bit.ly/2fIk4pz [Accessed 11-2016].

Osório, B., McCullen, N., and Walker, I. (2015) Urban transport: analysis of commute energy use. In: Brebbia, C. A. (ed.) Sustainable Development. Volume 168 of WIT Transactions on the Built Environment. New Forest, UK, WIT Press, pp. 855-865. 
Osório, B., McCullen, N., Walker, I., and Coley, D. (2016) Integrating the energy costs of urban transport and buildings. In preparation.

Portugali, J., Meyer, H., Stolk, E., and Tan, E. (eds.) (2012) Complexity theories of cities have come of age: An overview with implications to urban planning and design. Berlin, Germany, Springer.

Poumanyvong, P. and Kaneko, S. (2010) Does urbanization lead to less energy use and lower $\mathrm{CO}_{2}$ emissions? A cross-country analysis. Ecological Economics, 70 (2), 434-444.

Pumain, D., Paulus, F., Vacchiani-Marcuzzo, C., and Lobo, J. (2006) An evolutionary theory for interpreting urban scaling laws. Cybergeo: European Journal of Geography.

Qian, J. and Eglese, R. (2016) Fuel emissions optimization in vehicle routing problems with time-varying speeds. European Journal of Operational Research, 248 (3), 840-848.

Reinhart, C. F. and Davila, C. C. (2016) Urban building energy modeling - A review of a nascent field. Building and Environment, 97, 196-202.

Rybski, D., Reusser, D. E., Winz, A.-L., Fichtner, C., Sterzel, T., and Kropp, J. P. (2016) Cities as nuclei of sustainability? Environment and Planning B: Planning and Design, May, 1-16.

Samet, R. H. (2013) Complexity, the science of cities and long-range futures. Futures, 47, 49-58.

Schirmer, P. M. and Axhausen, K. W. (2015) A multiscale classification of urban morphology. Journal of Transport and Land Use, 9 (1), 101-130.

Schneider, A. and Woodcock, C. E. (2008) Compact, dispersed, fragmented, extensive? A comparison of urban growth in twenty-five global cities using remotely sensed data, pattern metrics and census information. Urban Studies, 45 (3), 659-692.

Schwarz, N. (2010) Urban form revisited - Selecting indicators for characterising European cities. Landscape and Urban Planning, 96 (1), 29-47.

Shim, G.-E., Rhee, S.-M., Ahn, K.-H., and Chung, S.-B. (2006) The relationship between the characteristics of transportation energy consumption and urban form. The Annals of Regional Science, 40 (2), 351-367.

Song, Y. and Knaap, G.-J. (2004) Measuring urban form: Is Portland winning the war on sprawl? Journal of the American Planning Association, 70 (2), 210-225.

Sperling, D. and Lutsey, N. (2014) Energy efficiency in passenger transportation. The Bridge, 44 (3).

Steinberger, J. and Weisz, H. (2013) City walls and urban hinterlands: The importance of system boundaries. In: Grubler, A. and Fisk, D. (eds.) Energizing Sustainable Cities: Assessing Urban Energy. Routledge, Chapter 4, pp. 41-56.

Stephan, A., Crawford, R. H., and De Myttenaere, K. (2012) Towards a comprehensive life cycle energy analysis framework for residential buildings. Energy and Buildings, 55, 592-600.

$\mathrm{Su}, \mathrm{Q}$. (2011) The effect of population density, road network density, and congestion on household gasoline consumption in US urban areas. Energy Economics, 33 (3), 445-452.

Tayyebi, A., Pijanowski, B. C., and Tayyebi, A. H. (2011) An urban growth boundary model using neural networks, GIS and radial parameterization: An application to Tehran, Iran. Landscape and Urban Planning, 100 (1), 35-44.

Tian, Y., Zhu, Q., Lai, K.-h., and Venus Lun, Y. (2014) Analysis of greenhouse gas emissions of freight transport sector in China. Journal of Transport Geography, 40. 
Travesset-Baro, O., Gallachóir, B. P., Jover, E., and Rosas-Casals, M. (2016) Transport energy demand in Andorra. Assessing private car futures through sensitivity and scenario analysis. Energy Policy, 96, 78-92.

Tsai, Y.-H. (2005) Quantifying urban form: Compactness versus 'sprawl'. Urban Studies, 42 (1), 141-161.

Tso, G. K. and Guan, J. (2014) A multilevel regression approach to understand effects of environment indicators and household features on residential energy consumption. Energy, 66, 722-731.

UN-DESA. (2014) World urbanization prospects: The 2014 revision, Highlights. New York, USA, United Nations: Department of Economic and Social Affairs.

Walker, I. (2010) Research methods and statistics. Palgrave Macmillan.

Wang, M. (2008) The Greenhouse Gases, Regulated Emissions, and Energy Use in Transportation (GREET) model: Version 1.5. Center for Transportation Research, Argonne National Laboratory. Technical report.

Wang, J. (2015) Resilience of self-organised and top-down planned cities - A case study on London and Beijing street networks. PloS One, 10 (12), 1-20.

Weng, Q., Liu, H., and Lu, D. (2007) Assessing the effects of land use and land cover patterns on thermal conditions using landscape metrics in city of Indianapolis, United States. Urban Ecosystems, 10 (2), 203-219.

Williams, K. (2014) Urban form and infrastructure: A morphological review. Government Office for Science. Technical report.

Yin, X., Chen, W., Eom, J., Clarke, L. E., Kim, S. H., Patel, P. L., Yu, S., and Kyle, G. P. (2015) China's transportation energy consumption and $\mathrm{CO}_{2}$ emissions from a global perspective. Energy Policy, 82, 233-248. 
